\title{
Poly cystic ovarian disease (PCOD) - a modifiable risk factor of infertility: A quasi-experimental research from South India
}

Betty KD*

*Corresponding author:

Ms. Betty KD, M.Sc, Lecturer, Department of Child Health Nursing, St. James College of Nursing, Chalakudy, Kerala, India.

Email: bettyroypunneli@gmail.com ORCID

Information about the article:

Received: Jan. 17, 2019

Accepted: Feb. 20, 2019

Published online: Dec. 27, 2019

Publisher

Nepal Health Research Society, Bahundhara -6, Gokarnesowor Municipality, Kathmandu, Nepal eISSN 2382-5545, ISSN 2676-1343 (Print)

(C) The Author(s). 2019

Content licensing: CC BY 4.0

\begin{abstract}
\section{Background}

India has a population of 1.2 billion, nearly 30 million couples in the country suffer from infertility, in which female infertility is caused mainly by PCOD (40\%). In Kerala, adolescent girls' population comprises $7 \%$ and the prevalence is 15\% (Annual vital report of statistics report 2015). The unhealthy eating habits and lack of exercise leads to PCOD. Therefore, as a nurse, the investigator has a pivotal role in creating awareness about the modification of lifestyle and prevention of future complications. The investigator observed that many students are diagnosed with PCOD during their physical training screening.
\end{abstract}

\section{Materials and methods}

Quantitative research approach, using quasi-experimental one group pre-test - post- test design was adopted to collect data by non-probability convenient sampling from 48 adolescent girls between 17-20 years those who were studying first year B.Sc. nursing in a private nursing college, Kerala. Demographic characteristics were age, religion, weight, family history, previous knowledge and knowledge questionnaire consisted of 30 questions with 4 options regarding poly cystic ovarian disease.

\section{Results}

Out of 48 subjects, majority (79.2\%) were in the age group of $19-20$ years, $47.9 \%$ were in the group of weight from 50 $60 \mathrm{~kg}$ and 33.3\% had menstrual problems. Majority 89.6\% were not having family history and only $38.3 \%$ had previous knowledge. Pre- test showed that majority (97.91\%) had average level of score, whereas in the post test majority (91.6\%) adolescents had good knowledge regarding poly cystic ovarian disease. The calculated t value 19.79 at 0.05 level of significance indicated that the structured teaching programme was effective. The chi- square value was lower than the table value at 0.05 level showed that there was no significant association between knowledge and their selected demographic variables.

\section{Conclusion}

Structured teaching programme regarding had improved the knowledge level of adolescent girls about poly cystic ovarian disease.

\section{Key words}

Adolescent girls, effectiveness, knowledge, poly cystic ovarian disease, quantitative research, structured teaching programme. 